\title{
EDITORIAL
}

\section{A Shift to the Left: Teaching the Craft of Cardiac Surgery}

\section{Curt Tribble, MD}

Division of Thoracic and Cardiovascular Surgery, University of Virginia Health System, Charlottesville, Virginia, USA

\section{INTRODUCTION}

Most of you know by now that the most difficult thing about surgery - even beart surgery - is getting a chance to do it. - Norman Shumway, MD, PhD, AATS Presidential Address, 1987

I was in Chicago in 1987 when Dr. Shumway delivered his American Association for Thoracic Surgery (AATS) presidential address, and, like most in the audience, I knew he was correct. Having had the privilege of getting to do a lot of thoracic and cardiovascular surgery in my surgical training, I was preparing myself to make my own move to the left side of the operating table. In fact, I had already resolved that I would make my own "shift to the left" very soon after that meeting in 1987, hoping to become, like Dr. Shumway, the best first assistant I could be. Over thirty years later, I have never looked, nor moved back. However, making this move to the left side of the table - to teach surgical residents how to operate - is challenging for many surgeons in academic environments. In considering the challenges, we must remember that those of us who have agreed to teach our protégés have an obligation both to them, and to their future patients, to help them become safe, capable cardiothoracic surgeons.

I am not bere to teach you facts. If you want facts, read my book. I am bere to teach you bow to think. - Tinsely Harrison, MD, Former Chair of Medicine at the University of Alabama

Dr. Harrison's famous quip is applicable to medical residents. The equivalent admonition from surgical educators to surgical trainees might be: "We are not here to teach you facts that you can learn from books. We are here to teach you how to operate." In addition to pointing out that they cannot learn surgery from books, we also acknowledge that they cannot learn to operate by watching others do it. One surgical training program's website colorfully summarizes these realities: "All doctors are book smart, but we don't cut patients open with books. Their lives literally lie in our hands."

To achieve great things, you need two things: a plan and a limited amount of time. - Leonard Bernstein, Former Director of the New York Philharmonic

\footnotetext{
Correspondence: Curt Tribble, MD, Professor of Cardiotboracic Surgery, University of Virginia Health System, Division of Thoracic and Cardiovascular Surgery, Box 800679, Charlottesville, VA 22908; 434-243-9250 (e-mail: CGT2E@bscmail.mcc.virginia.edu).
}

One of those challenges is that the amount of time available for the training of our residents in cardiothoracic surgery is fairly limited. In the orientation of our incoming senior cardiothoracic residents, my colleagues and I point out that they have about two years to learn approximately as much medicine and surgery as they have learned in their entire educational trajectories up to that point.

And we tell our trainees that we have a plan to help them become capable of doing heart surgery during that limited time, which will include "getting a chance to do it." However, as all who work in this realm know, there are challenges to this process beyond the time constraints. These challenges include the intense scrutiny of outcomes, the ethics of surgical education, and learning the strategies that can be utilized by those who train surgical residents. Therefore, I will outline some approaches to these challenges and some strategies that may be useful to those who have committed to helping trainees achieve competence in operative cardiothoracic surgery by shifting to the left side of the operating table.

\section{DEALING WITH THE INTENSE SCRUTINY OF OUTCOMES IN CARDIOTHORACIC SURGERY}

The majority of our patients do well but not by much. - - Irving Kron, MD, AATS Presidential Address, 2011

Practicing cardiothoracic surgeons and cardiothoracic surgical programs are very aware that their surgical outcomes are publicly reported and compared to what is generally expected in risk adjusted databases. Therefore, it is helpful to be reminded that the outcomes for cardiothoracic surgical patients cared for in academic environments are generally as good as, or even better than, those cared for in non-academic or private practice environments [Yount 2017].

We in Palo Alto often see foreign visitors on their way home who have spent varying periods of time at the Texas Heart Institute. When they leave Houston they think only Denton Cooley can do a particular operation, but when they leave Palo Alto they think anyone could do it. - Norman Shumway, MD, AATS Presidential Address, 1987

In the academic environment, patients will occasionally ask if trainees will be involved in their care. Besides pointing out the published data on the proven safety of receiving care in teaching environments, one can also note that in private practice environments, the surgeon of record is most often operating without the assistance of another 
surgeon, while in an academic environment, the assistant will generally be a trainee with 10 to 15 years of formal higher education and training. Another way of discussing this issue with patients and their families is to point out that the outcomes of one's system are publicly available and that these outcomes have been achieved in the environment, as it is organized at that institution. Most patients will be comfortable knowing that the protocol for care is the same as it always is, every single day. As an example of how this line of questioning can play out, I once found myself talking to one of the wealthiest men in the world who had been referred to me to discuss an aortic valve replacement that had been recommended by his cardiologist. The man's wife asked, "You won't have any students or residents involved in this operation, will you?" I turned to the patient and asked him, "If we do your operation here, would you like us to do it the same way we do it every day...or in some other way?" He did not hesitate, even for a moment, before answering, "Same way as every day, as I know that anything other than that is likely to not be as good as your routine practice." After this clinic visit, the patient notified me that he wanted to have his operation done at our institution under the most routine circumstances possible, again acknowledging his understanding that any plan that deviated from our routine would likely not be as good.

Another valid point, with data to support it, is that patients fare best in hospitals that manage postoperative difficulties effectively. The concept of dealing suboptimally with these difficulties has been called "Failure to Rescue." There is growing literature about this concept, and there is evidence that patients who are cared for in teaching hospitals are more likely to be rescued should postoperative complications or difficulties arise [Ghaferi 2010; Reddy 2013].

On a related note, there is increasing attention given to whether patients understand that trainees will be involved in their care. I believe that it is important to have the surgical residents who will be involved in the cases meet the patients prior to their operations whenever possible. As a resident myself, I eventually came up with what I still believe is an efficient and accurate way for trainees to introduce themselves to patients, which is to have them say, "I am Dr. X, and Dr. Y has asked me to help him with your operation and with your postoperative care." This straightforward statement identifies the resident by name and acknowledges several important facts, including: Who the attending surgeon is; that the attending must need help; and that the attending has deemed this particular resident capable of providing that help.

As a resident, once I settled on the precise wording of the introduction, I virtually never had a patient or family member ask me who was in charge, who would be doing the operation, or what my role would be because all of that information had been made clear in my introduction. After I became a faculty surgeon, I used similar language in talking with the patient and family, not only to reinforce their understanding of the chain of command, but also to designate the resident as an important and trusted part of the team, especially during interactions with the patient and family in the postoperative period [Tribble 2017].
An example of the benefit of having residents involve in the care of complex patients is colorfully illustrated by the following statement, supposedly uttered on occasion by faculty surgeons at the completion of a difficult operation: "This really complicated patient will require all that the two of us can do for him, and I have just done my part," which alludes to the reality that the resident will likely be the point person for the operative team during the anticipated challenging recovery period and likely nearby much of the time.

\section{THE ETHICS OF TEACHING SURGERY}

Professionalism is a declaration of a way of life in which expert knowledge is used not primarily for personal gain, but for the benefit of those who need the knowledge. -Edmund Pellegrino, MD

Surgeons who teach residents have an ethical obligation to educate and train safe surgeons [Parsa-Parsi 2017]. I learned an ethical concept from Dr. Edmund Pellegrino, who was one of this country's best known medical ethicists prior to his death a few years ago. He designated this concept as "collective advocacy," which he described as the obligation of physicians to contribute to the health of the general public [Pellegrino 2002]. To be accurate, he described this obligation mostly in terms of public health issues, such as clean water, free clinics, or vaccination programs. However, as a teacher of surgical practitioners, I have always taken Dr. Pellegrino's concept of collective advocacy to include an obligation to the public who will eventually be cared for by our trainees. In fact, our public accepts, at least tacitly, the fact that all practitioners will increase their wisdom and skills throughout their careers. Therefore, I believe that Dr. Pellegrino's concept of collective advocacy can be applied to the teaching of surgery. The ethical obligation that teaching residents imposes on us, the teachers, is that we create environments in which we manage the incremental advances of our trainees while under our auspices. Most experienced teachers of surgery have learned how to let their trainees take the next logical step in their training trajectories. This benefit to future patients was explicitly described by a patient whose life was saved with an emergency operation done by one of our former trainees, when this patient volunteered to send a photographic note of thanks to us, our trainee's teachers [Figure].




Every damn thing is your fault, if you're any good. - Ernest Hemingway

Of course, at the end of the day, every attending surgeon is well aware that he or she is ultimately responsible for every nuance of the care of the patients under their auspices, even when they are not physically present at the bedside.

\section{THE LANGUAGE OF TEACHING SURGERY}

If you can't explain it simply, you don't understand it well enough. —Albert Einstein

A teacher of surgery must be able to articulate accurately and effectively what he or she wants to have happen during an operation [Tribble 2014]. I myself found that it took a while, working on the left side of the operating table, to find just the right words to say that would result in virtually every resident doing what I wanted him or her to do. Another aspect of talking to a trainee who is doing a case with your help is to talk more before or after they have placed a stitch rather than commenting while they are placing it. Utilizing this rhythm of conversation will help prevent the resident from pausing, or having a "hitch" while sewing. While maintaining this rhythm can be challenging, it is essential in helping the trainee learn to move along expeditiously. It is also reasonable to point out the validity of the old adage that "perfection is the enemy of good." As the supervising surgeon, one must decide with virtually every stitch if it is acceptable or not. I have often chuckled about how this process can be somewhat similar to "seasickness." Seasickness is caused by the discrepancy between two sensory inputs (what is seen and what is felt), and the analogy in surgery is the discrepancy between what you had hoped to see and what you are actually seeing. As faculty surgeons, we must learn to manage this "seasickness" appropriately, deciding when something that might be a bit less than perfect is, nonetheless, acceptable.

Another aspect of the use of language while teaching during operations is that, when you the teacher do take on some part of the operation that is challenging for the resident, you should talk aloud about what you are doing and why you are doing it that way. These situations will arise from time to time. In fact, a good teacher will have a sense of when to take a stitch or do something else to facilitate the safe and expeditious completion of the operation. An example might include taking over the suturing of a very small coronary artery, the crucial toe stitches of a difficult coronary anastomosis, or the annular stitches in the right coronary sinus in an aortic valve replacement.

It is worth noting that finding a variety of ways to make salient points for our trainees can enhance their ability to remember them. Pat Conroy gives a colorful description of this strategy in The Lords of Discipline, in which he outlined his "Great Teacher Theory" writing that "it was a cornerstone of the theory that great teachers had great personalities and that the greatest teachers had outrageous personalities...I preferred a highly oxygenated atmosphere, a climate of intemperance, a feverish melodrama" [Conroy 1980]. While most teaching surgeons might draw the line just shy of intemperance and melodrama, it is hard to argue with the premise that colorful conversations are more memorable than the shifting dullness that would be on the other end of the spectrum of such conversations.

There are two kinds of residents: those who write things down and those who forget. - Hermes Grillo, Massachusetts General Hospital, Boston

It also eventually dawned on me, early in my career, that there were other ways to enhance communication with the trainees, such as asking them to discuss or even write out ahead of time what they planned to do for a given operation, rather than merely show up in the operating room expecting to be told precisely what needed to be done. Another mechanism to enhance the learning opportunities of each case is to ask that the residents write out their reflections on each case after its completion. Dr. Frank Spencer, in The Gibbon Lecture that he gave at the 1979 meeting of the American College of Surgeons, said that he dictated a letter of reflection to himself on each and every case after he had dictated the operative note. Writing notes of reflection after procedures, especially if they facilitate subsequent discussions, is, in my opinion, much more valuable than a perfunctory debriefing immediately after the operation is completed [Spencer 1979; Tribble 2016].

The slow, focused work of translating elusive perceptions about the why of craft into language, one tentative word at a time, bas taken surprising turns. Every statement has provoked new questions, until finally I have found myself mapping out terrain hitherto invisible to me. - Peter Korn, Why We Make Things \& Why It Matters: The Education of a Craftsman [Korn 2013]

\section{SAME WAY EVERY DAY}

I have spent considerable time across the table from young surgeons who were developing their clinical skills, giving me time to consider the so-called larger picture —Norman Shumway, $M D, P b D$, AATS Presidential Address, 1987

During a course on how to perform the Ross procedure, Dr. John Brown, the Chief of Cardiothoracic Surgery at the University of Indiana at the time, while demonstrating the operation on camera, apologized to the audience of surgeons participating in the course for the fact that he was doing the operation from the left side of the operating table. He said, "I am always on the left side of the table, as I am almost always helping a trainee operate. If I were on the right side for this demonstration, everything would just be upside down for me." Dr. Brown's point is one that I, and many others who teach residents how to do cardiothoracic surgery, agree with completely. A teaching surgeon should be able to do virtually every operation from the left side of the operating table. And, once one has made this "shift to the left" and become comfortable doing and teaching cardiothoracic surgery from this side of the table, it should actually be at least somewhat uncomfortable to be on the right side.

Some years ago, I was in a place where one had to drive on the left side of the road. I recognized that doing so was distinctly unfamiliar for me, so I told my wife and sons that all five 
of us had to be vigilant about staying on the left. Things were going fine until we had to turn around after missing a turn. I initially started back, after turning around, driving on the right side of the road, and the only person in the car who noticed was our youngest son who was not yet of driving age and was therefore not used to driving on the right. After laughing at ourselves a bit, I thought of the similarity of this situation to that described by Dr. Brown when apologizing for being on the left side of the operating table, and I was reminded again that no apology had been necessary.

\section{OTHER WAYS TO FACILITATE THE SHIFT TO THE LEFT OF A YOUNGER COLLEAGUE}

Most people can bandle one job at a time. Many bighly skilled and well-trained people can accomplish two tasks at a time. - Robert L. Shaw in Fighter Combat: Tactics and Maneuvering

It has often been said that the first few years after completion of training entail navigating the steepest learning curve of one's career. Recognizing this reality, it can be very helpful to a young faculty colleague for a more senior colleague to second assist on cases when the younger surgeon is making the shift to the left side of the table. In this situation, the more senior surgeon can be helpful to the younger surgeon and the trainee by running the room to minimize distractions for the two surgeons who are doing the operation, because, as Robert Shaw points out in his treatise on training jet fighter pilots, even well-trained people are challenged by dealing with multiple simultaneous tasks [Shaw 1985]. There are generally about five other groups of participants in a typical cardiac operation, including the perfusionists, the anesthesia team, the scrub nurses, the circulating nurse, and the physician assistants. Furthermore, there are often pages to answer. If the more senior surgeon can manage all of these other people and activities, the resident who is operating and the younger surgeon who is first assisting can focus almost completely on accomplishing the technical aspects of the operation with minimal distraction.

Another strategy that those with less teaching experience can focus on is optimal cardiac protection, including, for example, the use of both retrograde and antegrade cardioplegia, which can allow the operating team a bit of additional comfort if an operation seems to be proceeding a bit more slowly than it might if a more senior surgeon were throwing every stitch. Similarly, learning to provide the optimal exposure for various operations can facilitate the teaching of the less experienced residents, such as learning all the techniques for exposing each coronary territory or for optimizing visualization of the mitral valve. Finally, the teaching surgeon must become confident in his or her ability to achieve hemostasis safely and expeditiously.

There is also value in having the faculty surgeons create their own write-ups of their preferred techniques for many of the basic intraoperative techniques and maneuvers, as many of these basic techniques are rarely, if ever, covered in the standard cardiothoracic surgical techniques books.
This sort of write-up can facilitate learning and also expedite most operations when read and understood by the trainees prior to the planned operation. An example of this sort of treatise is one that we created at our institution for performing reoperative cardiac surgery, which is addressed only superficially, if at all, in most currently available techniques books.

The training program can also place an emphasis on having more senior residents scrub with the more junior faculty surgeons, as the more experienced residents can make a given operation move along more expeditiously in that situation, and this can also challenge them, the more senior residents, to become a bit more independent themselves. Furthermore, these more senior residents can pass along tips and strategies that they have learned from other faculty surgeons or in other training environments to a less experienced faculty surgeon. Having more senior residents work with the more junior attendings runs somewhat counter to the very common practice of the more senior residents scrubbing primarily on the cases of the more senior faculty surgeons.

\section{Conclusion}

Out of intense complexities, intense simplicities emerge. Winston Churchill

One of my former residents, Dr. Brian Clark, who is now a faculty surgeon in an institution with a cardiothoracic training program, summarized succinctly in a note to me many of the thoughts I have included in this treatise, and I have included an abridged version of his comments here:

"As academic surgeons at a teaching hospital, we have multiple professional duties. We have a duty to our patients to provide them with excellent care. Therefore, there will certainly be components of that care that should most appropriately be performed by the attending surgeon.

We also have a duty to provide our residents with the training we promised them. By recruiting and accepting trainees, we are entering into a social and professional contract with those trainees. We are promising to do our part, to hold up our end of the bargain, and provide them with an excellent educational experience. Finally, as teaching professionals, we have a duty to society to produce safe and competent surgeons to carry on the practice of cardiothoracic surgery. We are members of a profession, and professions are distinguished by, among other things, their obligations to society. In our case, that duty includes training competent surgeons to care for their future patients. As academic surgeons, we are expected to fulfill this duty. We should all do our jobs."

In summary, a surgeon who teaches residents has a limited time in which to train a safe and competent surgeon. Each teacher of surgery must find ways to allow each trainee take the next logical step in their training trajectory virtually every time they set foot in the operating room. In addition, each faculty surgeon must learn how to explain, set up, and assist on those steps. We, the teachers of our 
residents, have an obligation not only to the patient of the moment but also to all future patients of our trainees.

Through your progeny, you shall inherit eternity. -Owen Wangensteen, Former Chair of Surgery, The University of Minnesota

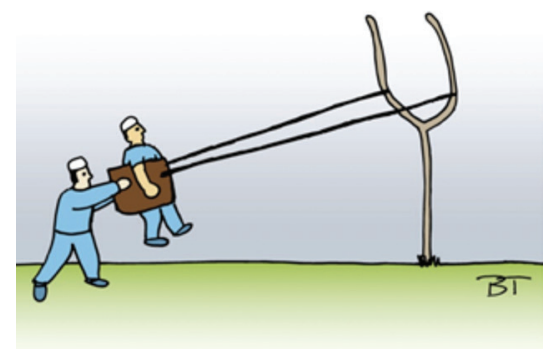

ACKNOWLEDGEMENTS

This manuscript is based, at least partially, on an invited lecture given during a Thoracic Surgery Directors Association retreat held in New Orleans in 2002.

I would be remiss if I did not recognize some of the simply splendid teachers of surgery with whom I have had the privilege to work and learn, including, at a very young age, my own father, David Tribble, and continuing with many others from J. Patrick O'Leary, Wayne Wilson, to Scott Jones, Brad Rodgers, George Minor, Stan Nolan, Irv Kron, and many others. Furthermore, I believe that I have learned almost as much from my many outstanding resident colleagues as they learned from me, including, to name just a few, Kent Harman, Warren Glover, Alan Johnson, Reid Tribble, John Kern, Scott Arnold, Randy Green, Ben Peeler, Jay Gangemi, Brian Clark, Gorav Ailawadi, and a great many others.

\section{REFERENCES}

Conroy P. 1980. The Lords of Discipline. Houghton Mifflin. ISBN-10: 1469235870 .

Ghaferi A, Osborne N, Birkmeyer J, Dimick J. 2010. Hospital characteristics associated with failure to rescue from complications after pancreatectomy. J Am Coll Surg 211:325-30.

Korn P. 2013. Why We Make Things and Why It Matters: The Education of a Craftsman. Boston: David R. Godine, Publisher. ISBN 978-1-56792-546-3.

Kron I. 2011. Surgical mentorship. J Thorac Cardiovasc Surg 142:489-92.

Parsa-Parsi R. 2017. The revised Declaration of Geneva: A modern day physician's pledge. doi: 10.1001/jama.2017.2017.16230

Pellegrino E. 2002. Professionalism, profession and the virtues of the good physician. Mt Sinai J Med 69:378-84.

Reddy H, Shih T, Englesbe M, et al. 2013. Analyzing "Failure to Rescue:" is this an opportunity for outcome improvement in cardiac surgery? Ann Thorac Surg 95:1976-81.

Shaw R. 1985. Fighter Combat: Tactics and Maneuvering. U.S. Naval Institute, Annapolis, Maryland. ISBN 0-87021-059-9

Shumway N. 2011. Some thoughts from the other side of the table or the last presidential address. J Thorac Cardiovasc Surg 142:1296-8.

Spencer F. 1979. Competence and compassion, The John H. Gibbon Lecture. Bull Am Coll Surg November:15-22.

Tribble C, Merrill W. 2014. The way we talk is the way we teach. J Thorac Cardiovasc Surg 147:1155-9.

Tribble C, Merrill W. 2016. In your own words: towards a more perfect union of patient care and education. Ann Thorac Surg 101:837-40.

Tribble C. 2017. Grandmother rules. Heart Surg Forum 20:1-5.

Yount K, Yarboro L, Narahari A, et al. 2017. Outcomes of trainees performing coronary artery bypass grafting: does resident experience matter? Ann Thorac Surg 103:975-81. 